\title{
BMJ Open Exploring risk of experiencing intimate partner violence after HIV infection: a qualitative study among women with HIV attending postnatal services in Swaziland
}

Claire Mulrenan, Manuela Colombini, Natasha Howard, Joshua Kikuvi, Susannah H Mayhew, on behalf of the Integra Initiative

To cite: Mulrenan $\mathrm{C}$, Colombini M, Howard N, et al. Exploring risk of experiencing intimate partner violence after HIV infection: a qualitative study among women with HIV attending postnatal services in Swaziland. BMJ Open 2015;5:e06907.

doi:10.1136/bmjopen-2014006907

- Prepublication history for this paper is available online. To view these files please visit the journal online (http://dx.doi.org/10.1136/ bmjopen-2014-006907).

Received 13 October 2014 Revised 21 February 2015 Accepted 6 March 2015

\section{CrossMark}

Department of Global Health and Development, London School of Hygiene and Tropical Medicine (LSHTM), London, UK

\section{Correspondence to} Dr Manuela Colombini; manuela.colombini@Ishtm. ac.uk

\section{ABSTRACT \\ Objective: To explore risks of experiencing intimate partner violence (IPV) after HIV infection among women with HIV in a postnatal care setting in Swaziland.}

Design: A qualitative semistructured in-depth interview study, using thematic analysis with deductive and inductive coding, of IPV experiences after HIV infection extracted from service-integration interview transcripts.

Setting: Swaziland.

Participants: 19 women with HIV, aged 18-44, were purposively sampled for an in-depth interview about their experiences of services, HIV and IPV from a quantitative postnatal cohort participating in an evaluation of HIV and reproductive health services integration in Swaziland.

Results: Results indicated that women were at risk of experiencing IPV after HIV infection, with 9 of 19 disclosing experiences of physical violence and/or coercive control post-HIV. IPV was initiated through two key pathways: (1) acute interpersonal triggers (eg, status disclosure, mother-to-child transmission of HIV) and (2) chronic normative tensions (eg, fertility intentions, initiating contraceptives).

Conclusions: The results highlight a need to mitigate the risk of IPV for women with HIV in shorter and longer terms in Swaziland. While broader changes are needed to resolve gender disparities, practical steps can be institutionalised within health facilities to reduce, or avoid increasing, IPV pathways for women with HIV. These might include mutual disclosure between partners, greater engagement of Swazi males with HIV services, and promoting positive masculinities that support and protect women.

Trial registration number: NCT01694862.

\section{INTRODUCTION}

Intimate partner violence (IPV) has gained increased recognition as a global public

\section{Strengths and limitations of this study}

- The first study to explore intimate partner violence (IPV) qualitatively from the perspective of Swazi women living with HIV.

- Adds to a growing literature suggesting that HIV infection contributes to IPV risk.

- Offers a conceptual framework, highlighting two potential risk pathways, to inform future research.

- The limited number of participants and specific context (ie, postnatal care setting) limit the generalisability and indicate the need for further research.

health concern. ${ }^{12}$ The WHO defines IPV as the reported experience of one or more acts of physical and/or sexual violence by a current or former sexual or marital partner. ${ }^{2}$ Most definitions include psychological violence and coercive control (eg, humiliation, isolation, asset control, threats, aggression, stalking) by current or former partners. ${ }^{3-7}$ Recent global estimates suggest that $30 \%$ of women experience IPV over their lifetime, with higher estimates of $37 \%$ found in the WHO Africa region. ${ }^{2}$ A concern in its own right, IPV is additionally associated with a range of adverse physical and mental health outcomes, including injuries, adverse birth outcomes, substance misuse, suicide and HIV infection. ${ }^{2} 89$

While several explanatory theories have been proposed for IPV, currently the most prominent approach is the ecological framework-developed from Bronfenbrenner's original ecological systems theory-in which key macro, community, interpersonal and individual constructs can interact within and across levels to shape the likelihood of IPV 
perpetration. ${ }^{10}{ }^{11}$ Thus, men and women bring their genetic endowments, personality traits and life experiences to a relationship, which is itself embedded in household and community microsystems and mesosystems embedded in the political, economic and cultural macrosystem. All interact and can increase or reduce probabilities for abuse. ${ }^{10}$ Within this framework, factors considered particularly relevant for IPV range from gender norms relating to male authority and female subordination to experiences of childhood violence and substance misuse. ${ }^{10}$

An increasing literature documents associations between IPV and HIV, ${ }^{12}$ framing IPV as both a risk factor for and consequence of HIV. ${ }^{7}{ }^{13-18}$ Significant overlap exists, with common risk factors including poverty, infidelity and multiple partners. ${ }^{19}$ Risk pathways can be direct: for example, forced sex confers increased biological vulnerability to HIV infection. ${ }^{16}{ }^{20}$ A prospective cohort study in South Africa found that women experiencing physical abuse were $48 \%$ more likely to acquire HIV than those in non-violent relationships. ${ }^{21}$ Indirect risk pathways include examples of women experiencing IPV having reduced ability to negotiate safer sexual practices or increased sexual risk taking due to lack of autonomy or low self-esteem. ${ }^{16} 20$

A cross-sectional Tanzanian study found that women with HIV had twice the odds of reporting physical and sexual violence from partners than their HIV-negative counterparts, although the nature of prevalence data meant that the directionality of this relationship remained unclear. ${ }^{22}{ }^{23}$ Recently, a qualitative study in Johannesburg antenatal clinics found that HIV diagnosis during pregnancy and partner disclosure were common IPV triggers. ${ }^{18}$ Insufficient longitudinal research means causality (eg, whether abuse is primarily a consequence of, or risk factor for, HIV infection) remains debated. ${ }^{72425}$ A smaller but relevant literature explores HIV as a risk factor for IPV. ${ }^{26}$ Although results are context specific, studies in low-income settings consistently found higher IPV risk among women with HIV. ${ }^{7}$

Swaziland has the highest HIV prevalence in the world, estimated at up to $39 \%$ among pregnant women and $26 \%$ among adults in 2008. ${ }^{27}$ Little research has been conducted on IPV, although existing evidence suggests that its prevalence is high. ${ }^{27-29}$ A 2007 national household survey found that $21 \%$ of the women surveyed reported physical violence from their partner in the last year, and $68 \%$ considered physical violence against women a serious problem in their community. ${ }^{28}$ A limited focus on physical violence suggests that results may underestimate IPV. ${ }^{28}$ A 2009 child sexual abuse survey found that one-third of respondents aged 13-24 reported an incidence of sexual violence before age 18. ${ }^{29}$ The Demographic and Health Survey (DHS) data suggest that acceptance of abuse is high, with $38 \%$ of women and $41 \%$ of men reporting wife beating as justified in at least one of six specified scenarios. ${ }^{27}$ A 2012 qualitative study exploring male understanding of IPV found that traditional gender roles were a key driver of IPV in Swaziland. ${ }^{9}$ No equivalent research was identified that explored female Swazi perspectives on IPV. To begin addressing these gaps, this study aimed to explore IPV experiences subsequent to HIV infection among women with HIV in Swaziland.

\section{METHODS}

\section{Study design and participants}

A qualitative design was chosen, drawing on 19 in-depth interviews (IDIs) with women with HIV. IDI participants were purposively sampled, to ensure wide facility representation, from a quantitative cohort of 123 postnatal care attendees at 10 public health facilities participating in the Integra Initiative. The study design for Integra research on integration of reproductive health and HIV services in Kenya and Swaziland is detailed elsewhere. ${ }^{30}$ Table 1 summarises the demographics of participants and the cohort from which they were selected. The planned sample of 24 respondents (ie, 20\%) was not achieved because the selected participants declined consent (1) or could not be traced (4). The interview guide covered client experiences with integrated postnatal/HIV services. While the focus of the interview was not on violence, questions on HIV-related challenges, potential risks following disclosure and any IPV experiences were included.

\section{Data collection and analysis}

IDIs were conducted face to face in siSwati, in private locations selected by interviewees, by four trained female Swazi interviewers between November 2012 and April 2013. Written informed consent was obtained from all participants prior to interview. Interviews took approximately $1 \mathrm{~h}$. All interviews were audiorecorded, transcribed verbatim and translated from siSwati to English.

Data were analysed thematically, using deductive (eg, informed by study objectives and literature) and inductive (eg, emerging from and grounded in data) coding. ${ }^{31}$ A broad definition of IPV was used, encompassing sexual, physical, economic and psychological abuse. First, transcripts were closely and repeatedly read by CM for data familiarisation and narrative coding, to build an overall picture of participants' lives and provide context. Second, CM and MC separately performed thematic coding, using a matrix for each case to document IPV occurrences, association of occurrences with HIV status (and if so, how), and other emerging factors. Coding was then discussed with SM. Deviant cases were explored and an audit trail maintained to track development of ideas. Third, discrepancies were discussed with coauthors and local partners working in sexual and reproductive health in Swaziland. A coding hierarchy was adjusted and refined during analysis, until overarching themes were identified in discussions between $\mathrm{CM}$, MC and SM. Finally, emerging links and pathways provided the basis of final coding in Nvivo V.8 software. Reporting adheres to COREQ criteria for qualitative research. ${ }^{32}$ 
Table 1 Sociodemographic characteristics and selected responses for 19/123 women with HIV attending postnatal services in Swaziland

\begin{tabular}{|c|c|c|}
\hline Variables & $\begin{array}{l}\text { Participants } \\
n=19(\%)\end{array}$ & $\begin{array}{l}\text { Full cohort } \\
n=123(\%)\end{array}$ \\
\hline \multicolumn{3}{|l|}{ Age (years) } \\
\hline Mean (range 24-42) & 31 & 29 \\
\hline $15-20$ & $0(0)$ & $7(6)$ \\
\hline $21-30$ & $8(42)$ & $64(52)$ \\
\hline $31-40$ & $9(47)$ & $44(36)$ \\
\hline 41-45 & $2(11)$ & $8(7)$ \\
\hline \multicolumn{3}{|l|}{ Education } \\
\hline None & $1(5)$ & $3(2)$ \\
\hline Primary incomplete & $8(42)$ & $20(16)$ \\
\hline Primary complete & $1(5)$ & $20(16)$ \\
\hline Secondary incomplete & $5(26)$ & $49(40)$ \\
\hline Secondary complete & $2(11)$ & $25(20)$ \\
\hline $\begin{array}{l}\text { Post-secondary } \\
\text { incomplete }\end{array}$ & $2(11)$ & $5(4)$ \\
\hline $\begin{array}{l}\text { Post-secondary } \\
\text { complete }\end{array}$ & $0(0)$ & $1(1)$ \\
\hline \multicolumn{3}{|l|}{ Employment status } \\
\hline $\begin{array}{l}\text { Unemployed, not } \\
\text { seeking work }\end{array}$ & $7(41)$ & 22 (18) \\
\hline $\begin{array}{l}\text { Unemployed, seeking } \\
\text { work }\end{array}$ & $3(18)$ & $39(32)$ \\
\hline Unskilled employment & $5(25)$ & $32(26)$ \\
\hline Skilled employment & $3(16)$ & $26(21)$ \\
\hline Student & $0(0)$ & $4(3)$ \\
\hline \multicolumn{3}{|l|}{ Marital status } \\
\hline No relationship & $1(5)$ & $6(5)$ \\
\hline Separated/widowed & $2(11)$ & $3(2)$ \\
\hline $\begin{array}{l}\text { In a relationship living } \\
\text { separately }\end{array}$ & $3(16)$ & $49(40)$ \\
\hline Living with partner & $2(11)$ & $19(15)$ \\
\hline Married monogamous & $11(58)$ & $45(37)$ \\
\hline Married polygamous & $0(0)$ & $1(1)$ \\
\hline \multicolumn{3}{|c|}{ If discovered pregnancy tomorrow } \\
\hline Sad & $13(68)$ & $97(79)$ \\
\hline Happy & $0(0)$ & $1(1)$ \\
\hline $\begin{array}{l}\text { Would not mind/not } \\
\text { applicable }\end{array}$ & $6(32)$ & $25(20)$ \\
\hline $\begin{array}{l}\text { Number of children } \\
\text { wanted by partner }\end{array}$ & $n=16$ & $n=119$ \\
\hline Same as she wants & $6(38)$ & $45(39)$ \\
\hline More than she wants & $3(18)$ & $18(16)$ \\
\hline Fewer than she wants & $1(6)$ & $5(4)$ \\
\hline Unknown & $6(38)$ & $46(40)$ \\
\hline Partner's HIV status & $n=16$ & $n=119$ \\
\hline Living with HIV & $15(94)$ & $97(85)$ \\
\hline $\begin{array}{l}\text { Not living with HIV/ } \\
\text { unknown }\end{array}$ & $1(6)$ & $17(14)$ \\
\hline $\begin{array}{l}\text { Use of condoms in } \\
\text { addition to family planning } \\
\text { method }\end{array}$ & $n=15$ & $\mathrm{n}=82$ \\
\hline Never & $1(7)$ & $10(12)$ \\
\hline Sometimes & $11(73)$ & $38(46)$ \\
\hline Always & $3(20)$ & $34(42)$ \\
\hline
\end{tabular}

Ethics

Researchers were trained to follow ethical procedures and the WHO guidelines on ethics and safety in studies dealing with violence against women. ${ }^{33}$

\section{RESULTS}

Participant characteristics and IPV experiences are summarised quantitatively. Emergent themes (ie, acute interpersonal triggers, normative tensions) and deviant cases (ie, HIV as protective) are then presented with relevant quotes.

\section{Participant characteristics}

Although participants were somewhat less educated, more frequently unemployed/not seeking work and monogamously married than the postnatal cohort from which they were drawn, demographic characteristics were broadly comparable (table 1). The average reported age among the 19 participants was 31, ranging from 24 to 42 . While nearly all reported some education, only some had completed secondary school. Half reported that they were unemployed, and only a few were in skilled employment. Most were in a relationship. Most reported that they would feel sad if they discovered they were pregnant. Most either did not know their partner's preferred number of children or reported identical preferences. Among women with partners, nearly all had partners with HIV. Only one woman reported condoms as her primary family planning method. Of 15 women using other methods, most also reported using condoms either always or sometimes. Most had partners with HIV, though many learnt their own serostatus before that of their partner.

\section{IPV experiences after HIV infection}

Nine participants reported experiencing IPV post-HIV infection. Four of these disclosed direct physical or sexual IPV. The remaining five described experiencing coercive control and abuse, including manipulation (eg, blame for his infidelity), sexual coercion (eg, refusal to wear condoms, pressure to have intercourse) and abandonment on disclosure of status. Another four gave mixed/contradictory responses about their own experiences of IPV, possibly indicating experiences they were not comfortable discussing, while six reported no personal experiences of IPV.

Reported manipulation and coercion were common and varied, including blaming the woman for his behaviours and feelings, pretending to use condoms or applying emotional and physical pressure to have intercourse.

He ends up having sex outside the marriage and he would blame me that it's my fault because I refuse to have sex with him. (Participant 7, speaking of coercion experienced) 
The man at times would dodge and you would think maybe he has put the condom on and yet he didn't...At times you're forced [...] and then at times he will beg me up until I agree. (Participant 14, speaking of emotional abuse)

Many women were concerned that IPV exacerbated their HIV-related health concerns. Five women explicitly mentioned concerns about the effects of IPV-both physical and psychological-on their CD4 count and disease progression.

[IPV is a problem] because this will bring more stress to the woman and her CD4 count will drop and she will end up taking ARVs. (Participant 7, speaking of emotional abuse experienced)

If someone beats you up then you'll be stressed and then your CD4 count will go down and then you'll get ill. (Participant 12, speaking generally on IPV)

Exploring IPV risk after HIV infection among participants indicated two interrelated pathways: (1) acute interpersonal triggers and (2) chronic normative tensions, through which HIV seropositivity could increase IPV vulnerability and risk (figure 1).

\section{Acute interpersonal triggers}

These described circumscribed emotive events that can precipitate IPV. Two major HIV-related IPV triggers were discussed: (1) serodisclosure to partners and (2) HIV diagnosis for a couple's baby.

\section{Serodisclosure to partners}

Serodisclosure, which was often gendered asymmetrically (ie, with only 1 partner disclosing HIV status), commonly triggered emotional and sometimes physical reactions from male partners. Nearly all women reporting partner abuse had disclosed their status to their partner. Across a number of accounts, HIV disclosure by either

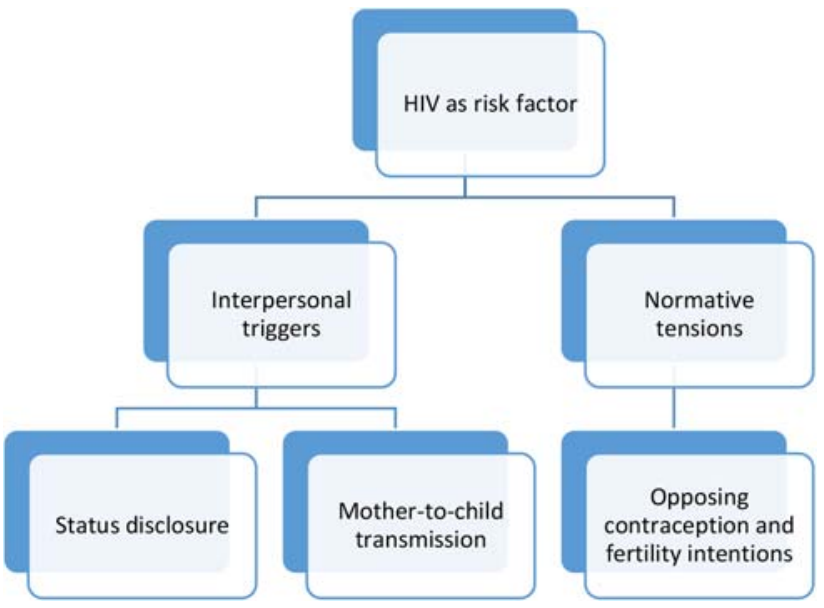

Figure 1 Conceptual framework describing triggers for post-HIV interpersonal violence. partner initiated emotional reactions and defensive rationalisations from partners involving blame, verbal hostility, rejection and potential violence.

Several discussed rejection and blame from partners, with participant 8 describing initial abandonment.

He talked, and said hurtful things, that I had infected him with the virus. (Participant 5)

I disclosed but then at the beginning there were problems...he said he doesn't know how we're going to continue under the circumstances...A week would go by without us seeing each other...It affected me because it happened when I had the baby. (Participant 8)

Two described experiencing physical violence following disclosure. The most severe was described by participant 2, after the interview recording stopped due to fears that her husband might hear the audio file. ${ }^{i}$ Direct quotes are unavailable, but she described how he "beat her to a pulp" following disclosure, then locked her in the basement to prevent her trying to contact the police. She miscarried shortly afterwards.

Men's blame and violence appeared to be worsened by disclosure asymmetry. Swazi women often test at antenatal care (ANC) so asymmetry was potentially gendered. Ten participants had partners who had initially not disclosed to them or refused to test, compared with just one who had not disclosed to her partner. Disclosure asymmetry enabled denial and blame, including accusations of infidelity, despite the reality that most women's partners were also infected.

It sometimes happens that if someone does not tell you his status, then he will tend to blame you...At first, I got a little scared because I actually thought I was the one who had in fact infected him, but then I let go of that thought when I found out that he was also infected. (Participant 5)

Participant 5 reported "he let it go and was okay" when he learnt she was aware of his status, suggesting mutual disclosure could potentially reduce conflict. This need for mutual disclosure was expressed by several participants, often in relation to health service failures to encourage partner testing and male engagement. Many highlighted a lack of counselling around disclosure and four described a need for health workers to engage male partners in the process. Participant 13 said health workers should '(counsel) men against abuse,' while participant 5 said health workers "should have encouraged me to come with him to the hospital and have him tested too."

iExplicit permission received to use 'off the record' information on condition that anonymity was maintained. 


\section{HIV diagnosis of children}

Diagnosis of mother-to-child transmission of HIV was the second major HIV-related trigger discussed. Only two participants had given birth to a baby with HIV, but for one this was associated with severe physical violence.

He would have killed me if his mother was not there, because he got very angry when he found out that even the baby had HIV passed on to her...He was carrying a bush knife saying he was going to hack me with it. (Participant 5)

While participant 5's partner appeared to accept her HIV status after learning she was aware of his seropositivity, discovering HIV transmission to their baby retriggered his violence.

\section{Normative tensions}

These described broader tensions between firmly established gender norms and clinical requirements for maintaining health and well-being with HIV. Normative tensions, between gender roles as mother and selfless caretaker versus self-care expectations of an HIV-positive identity, increased participant dependency and vulnerability. This potentially reduced her already limited autonomy (eg, through economic disempowerment, social stigma, self-esteem issues), increasing potential risks of experiencing coercive control and violence.

Transcripts provided a strong sense of community gender norms and expectations, particularly regarding fertility, where several highlighted childbearing as a matrimonial duty: "a wife must always have a baby" (participant 9). Additionally, men traditionally decided when and how to have sex. Thus, two major interrelated normative tensions were: (1) discordant fertility intentions and (2) condom usage.

\section{Discordant fertility intentions}

Discordant intentions within patriarchal gender norms meant that attempting to resist partners' and society's values around childbearing and male household authority exposed women to interpersonal conflict and potential violence. Two reported subversive approaches (eg, secretly using injections, sterilisation) to achieve fertility intentions while avoiding conflict.

Many participants described HIV diagnosis as negatively affecting their desire for more children, though none specifically stated that IPV had affected their fertility intentions. Over half reported wanting to avoid further pregnancies, with four explicitly linking changes in fertility intentions to HIV status. Changed fertility intentions were typically attributed to concerns around self-care (eg, negative effects of pregnancy on CD4 count and overall health) and/or care for others (eg, passing infection to an unborn child, orphaning children due to HIV-related premature death). The increased importance of avoiding pregnancy increased the perceived value of family planning services among women with HIV. Respondent 10 noted that contraception was "more important now" as giving birth at short intervals would negatively affect her CD4 count.

[...] my husband wanted us to have two kids, yet after I found out that I am HIV-positive I told myself that I will never have another one, because the more you have kids the more your CD4 counts drop so I don't want that for me. (Participant 7)

However, changes in women's fertility intentions did not necessarily coincide with their partner's intentions, potentially increasing risks of relationship conflict and IPV. Several participants indicated that men were responsible for final decisions around contraception and women had limited autonomy in determining contraceptive choice. Attempts to exert greater control over fertility appeared to clash with traditional gender roles and male responsibility for fertility decisions.

When he wants us to have a baby then we're going to have a baby, whether I like it or not. (Participant 9)

Participant 3 described trying to discuss family planning with her husband as he "doesn't take it serious and so I end up keeping my mouth shut." Participant 2 reported using the female condom "since my partner does not like the (male) condom".

Limited autonomy led at least two women to risky behaviours. Participant 2 described initially continuing injectable contraceptives that caused sickness. Participant 9 sought sterilisation without her partner's knowledge. She maintained that her husband was not abusive, but indicated that he made all family planning decisions and she was concerned about repercussions should he discover her subverting his wishes through seeking sterilisation.

\section{Condom usage}

Negotiating condom usage appeared particularly fraught. Participant 10 described men's condom usage as sporadic: "sometimes they do not want it." Attempting to influence men's condom usage from a traditionally subordinate position placed women at heightened risk of coercive control and violence, with four participants describing partners coercing or forcing them to have sex without a condom. It was unclear whether partner seroconcordance reduced men's willingness to use condoms.

There were instances whereby we, me and the baby's father, would fight because he would force me to have sex with him even when I do not feel like it...[long pause]... He would end up not using the condom. He used to beat me up and hurt me. (Participant 5)

\section{HIV as protective}

Although responses demonstrated complex HIV-IPV interactions and indicated that HIV may increase IPV 
risk, a notable deviant case suggested that HIV status can sometimes be protective. One participant described the support and avoidance of psychological violence that her husband provided as due to her HIV status.

$\mathrm{R}$ : When he realises that he is about to hurt me emotionally, he calms down.

I: Hurt you emotionally, how?

R: Things like shouting at me. Even if it had happened by accident, that he will shout at me, he quickly remembers and then he calms down...because...they told us we should avoid getting angry when we are on the ARV treatment. (Participant 10)

In this example, awareness of heightened vulnerability to abuse-related stress meant that HIV status could be a negotiation tool to avoid conflict. However, this case differed from others in several ways. First, there was no discordance in fertility intentions: "He is with me on that one, he feels like the two are enough." Second, despite accounts of female subordination (eg, "You find that females...are not able to voice their opinions better than the males...Males more often than not voice out valid opinions"), the relationship appeared more equitable: "...there were no major challenges, since we were a team, me and the baby's father." Finally, she was clear her husband was fulfilling his proscribed gender role as provider: "It is my husband who assists me by making sure that he provides me with the necessary food."

\section{DISCUSSION}

\section{Framing post-HIV IPV}

This study is the first to explore IPV qualitatively from the perspective of Swazi women with HIV. Although findings suggest IPV risk for women with HIV, caution is needed to prevent over-generalising this relationship. Seropositivity is one of many factors influencing IPV risk, including alcohol misuse, violence in childhood and situational (eg, infidelity) and patriarchal triggers (eg, assertion of female autonomy). ${ }^{10}{ }^{34}$ Nevertheless, the triggers of post-HIV IPV have not been well explored and our results offer a way to conceptualise these as shown in figure 1. This cognitive framework describes HIV status as a risk factor for IPV which can be triggered by acute interpersonal triggers (status disclosure and onward transmission to a baby) and by chronic normative tensions (overfertility and contraceptive decision-making). While it appears unlikely that HIV infection originated IPV in these relationships, seropositivity appeared to provide additional opportunities for violence.

\section{Acute triggers}

IPV research has focused on acute HIV-related risks, largely framed within the context of disclosure. ${ }^{18} 35$ Consistent with this, results suggest that serodisclosure can increase IPV risk. This is particularly apparent in the context of disclosure asymmetry and unknown partner status, enabling blame as further justification for violence. Results also suggest mother-to-child transmission (MTCT) of HIV as a potential IPV trigger. Although this arises less frequently than status disclosure triggers, the high reported rates of HIV MTCT in Swaziland indicate that it may require consideration. ${ }^{36}$

\section{Normative tensions}

This study highlights the need to consider normative pathways through which gender disparities may place seropositive women at increased IPV risk. Fewer studies have focused on risk within this broader context, ${ }^{37} 38$ despite general recognition of gender norms as important in shaping IPV in sub-Saharan Africa. ${ }^{33}$ Male virility and sexual decision-making have been identified as central to Swazi conceptualisations of masculinity. ${ }^{9} 39$ Given that many women expressed reduced desire for children following diagnosis, HIV may indirectly threaten traditional Swazi gender norms with potentially abusive or violent consequences (in which men dictate the number of children and generally have high fertility desires). This hypothesis was proposed by Kaye, ${ }^{19}$ but has not been explored in detail. Emphasis on family planning following HIV diagnosis, alongside attempts by women to increase fertility-related autonomy (eg, particularly related to condom usage), may heighten IPV risk. These issues deserve further programmatic and research consideration. Counselling should cover the pros and cons of partner disclosure and for those who have disclosed to their partner to encourage couple counselling/visits regarding contraceptive advice (ie, beyond condoms). ${ }^{40}$

For one participant, HIV seemed to protect against IPV and was used to negotiate reduced emotional stress. The potential detrimental effects of stress and fear on CD4 count were recognised by her partner, which in the context of a more egalitarian relationship seemed to impact positively on conflict resolution. This is the first documented case known to the authors of HIV as protective against IPV in a sub-Saharan African context, and highlights a need to frame IPV risk factors as 'probabilistic' rather than 'deterministic'. ${ }^{10}$

\section{Implications for research, policy and practice}

Results suggest that the relationship between HIV and IPV is complex and potentially cyclical, influenced by sociocultural factors (eg, gender hierarchies, economics). Further research is needed in the directionality of HIV and IPV interactions, influence of IPV on fertility intentions and contraceptive usage, potential impact of IPV on HIV disease progression, and ways to reduce IPV risk for women with HIV. Research on IPV's impact on HIV progression is still in its infancy, but concerns expressed by participants suggest that further investigation is needed.

Results have policy implications for postnatal care settings in Swaziland, given the high HIV prevalence of $39 \%$ 
among pregnant women. ${ }^{27}$ The need for mutual disclosure between partners was expressed by participants and documented elsewhere, ${ }^{19}$ but healthcare providers must consider that disclosure or serodiscordance may still trigger violence, resentment and fear of abandonment among women, as documented in studies from South Africa, Uganda and Tanzania. ${ }^{1841}{ }^{42}$ Seen in this light, healthcare providers should assess potential IPV risk before encouraging women to speak to their partners, or promoting couple counselling, and facilitate referral to support services if necessary, as recommended elsewhere. ${ }^{12} 39$

Practice implications include improved male engagement with healthcare services and thorough counselling, which may reduce IPV risk. However, research on effectiveness of counselling to reduce IPV is lacking and significant barriers exist to achieving this goal. In a country where traditional gender roles dictate that family economic provision is a male responsibility, ${ }^{43}$ fear of economic loss may represent a significant barrier to male testing and female disclosure, as fear of abandonment can contribute to test delay or refusal among women in sub-Saharan Africa. ${ }^{37}$ Health facilities are perceived as 'female spaces' in Swaziland, ${ }^{43}$ and limited male health services usage is reflected in low HIV testing rates. ${ }^{27} \mathrm{~A}$ recent increase in efforts to medically circumcise men in Swaziland may offer a potential opportunity for greater male engagement with HIV and health services. ${ }^{9}$

Aside from assessing and managing risk in the short term, improved links between postnatal services and community support may facilitate longer term support for women with HIV. Community-level and populationlevel interventions for women with HIV should focus on renegotiating gender roles and balancing fertility against their desire to avoid pregnancy. In the Swazi context of limited female autonomy, this may represent a huge challenge. The deviant case suggests encouraging positive masculinities, as emotional and material provider, could reduce IPV prevalence in the longer term as well as improving male health-seeking behaviour for HIV, as was found in a study on masculinity in Swaziland. ${ }^{39}$

Results have implications for HIV prevention programmes, which rely heavily on promotion of male condom usage and HIV testing and disclosure. ${ }^{21}$ Programmes may need to compensate for the reality that violence and fear of violence may restrict female compliance. IPV risk could be assessed to mitigate unintended consequences of additional iatrogenic violence. ${ }^{16}$

\section{Limitations}

An in-depth exploration of the reported experiences of a small number of women with HIV in a postnatal care setting is not generalisable to other groups and settings (eg, HIV-negative women, women without children). As IPV was not the main focus of interviews, this topic may have been insufficiently explored with some participants. Moreover, as data regarding prior IPV or IPV as a risk factor for HIV infection were unavailable, though supported by existing research, this study can only demonstrate unidirectional IPV risk for women with HIV. It was not possible to review transcripts and results with participants, though transcripts were reviewed with interviewers. Nevertheless, study findings offer additional insight and a novel conceptual framework to inform future research, adding to research evidence.

\section{CONCLUSION}

Results highlight acute interpersonal triggers and normative tensions that may increase IPV risk among women with HIV. Authors propose a conceptual framework to guide research on HIV and IPV, and highlight the need to mitigate IPV risk in planning and implementing HIV programmes. While a broader change is needed to resolve gender disparities in Swaziland, practical steps can be taken to reduce, or avoid increasing, IPV risk for women with HIV.

Acknowledgements The authors would like to thank the study participants for their time and the Bill and Melinda Gates Foundation for partially funding the manuscript preparation.

Contributors CM analysed the data as part of master's in public health research and prepared the manuscript. MC designed the study, contributed to the coding and data interpretation, and critically reviewed the manuscript. NH analysed the quantitative data, contributed to data interpretation, and critically revised the manuscript. JK contributed to the data collection and interpretation and critically reviewed the manuscript. SM contributed to the data coding and interpretation and critically reviewed the manuscript. All authors approved the submitted version.

Funding The study was funded by the Bill and Melinda Gates Foundation through the Integra Initiative (grant number 48733). The funder was not involved in the study design, data collection, analysis or interpretation.

\section{Competing interests None declared.}

Ethics approval Ethics approval was provided by the Scientific Ethics Committee of the Swaziland Ministry of Health (approval number MH/599C), the Research Ethics Committee of the London School of Hygiene \& Tropical Medicine (approval number 5426), and the Population Council institutional review board (approval number 444). The Integra Initiative is registered with Clinical Trials (ClinicalTrials.gov) as NCT01694862.

Provenance and peer review Not commissioned; externally peer reviewed.

Data sharing statement Study tools and data will be shared in accordance with LSHTM's Research Data Management Policy and stored in its institutional repository.

Open Access This is an Open Access article distributed in accordance with the Creative Commons Attribution Non Commercial (CC BY-NC 4.0) license, which permits others to distribute, remix, adapt, build upon this work noncommercially, and license their derivative works on different terms, provided the original work is properly cited and the use is non-commercial. See: http:// creativecommons.org/licenses/by-nc/4.0/

\section{REFERENCES}

1. Devries KM, Mak JYT, Garcia-Moreno C, et al. The global prevalence of intimate partner violence against women. Science 2013;340:1527-8

2. Garcia-Moreno C, Pallitto C, Devries K. Global and regional estimates of violence against women: prevalence and health effects of intimate partner violence and non-partner sexual violence. Geneva: World Health Organization, 2013.

3. Saltzman LE, Fanslow JL, McMahon PM. Intimate partner violence surveillance: uniform definitions and recommended data elements: Version 1.0. Atlanta, GA: Centers for Disease Control and Prevention, National Center for Injury Prevention and Control, 2002. 
4. Dutton M, Goodman L, Schmidt R. Development and validation of a coercive control measure for intimate partner violence: final technical report. US Department of Justice, 2006.

5. Stark E. Coercive control: the entrapment of women in personal life. In: Renzetti C, Eddleson J, eds. Interpersonal violence. New York, NY: Oxford University Press, 2007.

6. Cagney $\mathrm{H}$. Intimate partner violence and HIV: unwelcome accomplices. Lancet 2014;383:395.

7. Campbell J, Baty ML, Ghandour RM, et al. The intersection of intimate partner violence against women and HIV/AIDS: a review. Int J Inj Contr Saf Promot 2008;15:221-31.

8. Abramsky T, Watts $\mathrm{CH}$, Garcia-Moreno $\mathrm{C}$, et al. What factors are associated with recent intimate partner violence? Findings from the WHO multi-country study on women's health and domestic violence. BMC Public Health 2011;11:109.

9. Brear M, Bessarab D. Perspectives on intimate partner violence in Swaziland amongst 18-29-year-old men undergoing medical circumcision. Cult Health Sex 2012;14:31-43.

10. Heise L. What works to prevent partner violence? An evidence overview. STRIVE, 2011.

11. Bronfenbrenner $\mathrm{U}$. The ecology of human development: experiments by nature and design. Cambridge, MA: Harvard University Press, 1979.

12. Li Y, Marshall CM, Rees $\mathrm{HC}$, et al. Intimate partner violence and HIV infection among women: a systematic review and meta-analysis. $J$ Int AIDS Soc 2014:17:18845.

13. Anderson JC, Campbell JC, Farley JE. Interventions to address HIV and intimate partner violence in sub-Saharan Africa: a review of the literature. J Assoc Nurses AIDS Care 2013;24:383-90.

14. Coker AL. Does physical intimate partner violence affect sexual health? A systematic review. Trauma Violence Abuse 2007:8:149-77.

15. Kouyoumdjian FG, Calzavara LM, Bondy SJ, et al. Intimate partner violence is associated with incident HIV infection in women in Uganda. AIDS 2013;27:1331-8.

16. Maman S, Campbell J, Sweat MD, et al. The intersections of HIV and violence: directions for future research and interventions. Soc Sci Med 2000;50:459-78.

17. Zablotska IB, Gray RH, Koenig MA, et al. Alcohol use, intimate partner violence, sexual coercion and HIV among women aged 1524 in Rakai, Uganda. AIDS Behav 2009;13:225-33.

18. Hatcher AM, Woollett N, Pallitto CC, et al. Bidirectional links between HIV and intimate partner violence in pregnancy: implications for prevention of mother-to-child transmission. $J$ Int AIDS Soc 2014:17:19233.

19. Kaye D. Gender inequality and domestic violence: implications for human immunodeficiency virus (HIV) prevention. Afr Health Sci 2004:4:67-70.

20. Harling G, Msisha W, Subramanian S. No association between HIV and intimate partner violence among women in 10 developing countries. PLOS ONE 2010;5:e14257.

21. Jewkes RK, Dunkle K, Nduna M, et al. Intimate partner violence, relationship power inequity, and incidence of HIV infection in young women in South Africa: a cohort study. Lancet 2010;376:41-8.

22. Maman S, Mbwambo JK, Hogan NM, et al. HIV-positive women report more lifetime partner violence: findings from a voluntary counseling and testing clinic in Dar es Salaam, Tanzania. Am J Public Health 2002;92:1331-7.

23. Maman S, Mbwambo J, Hogan NM, et al. Women's barriers to HIV-1 testing and disclosure: challenges for HIV-1 voluntary counselling and testing. AIDS Care 2001;13:595-603.
24. Uthman OA, Lawoko S, Moradi T. Factors associated with attitudes towards intimate partner violence against women: a comparative analysis of 17 sub-Saharan countries. BMC Int Health Hum Rights 2009;9:14.

25. Gielen A, McDonnell K, O'Campo P. Intimate partner violence, HIV status, and sexual risk reduction. AIDS Behav 2002;6:107-16.

26. Shamu S, Abrahams N, Temmerman M, et al. A systematic review of African studies on intimate partner violence against pregnant women: prevalence and risk factors. PLOS ONE 2011;6:e17591.

27. CSO. Swaziland Demographic and Health Survey 2006-07. Mbabane: Central Statistics Office Swaziland, 2008.

28. Andersson N, Ho-Foster A, Mitchell S, et al. Risk factors for domestic physical violence: national cross-sectional household surveys in eight southern African countries. BMC Womens Health 2007;7:11.

29. Reza A, Breiding MJ, Gulaid J, et al. Sexual violence and its health consequences for female children in Swaziland: a cluster survey study. Lancet 2009;373:1966-72.

30. Warren CE, Mayhew SH, Vassall A, et al. Study protocol for the integra initiative to assess the benefits and costs of integrating sexual and reproductive health and HIV services in Kenya and Swaziland. BMC Public Health 2012;12:973.

31. Taylor SJ, Bogdan R. Introduction to qualitative research methods: the search for meanings. New York: John Wiley \& Sons, 1984

32. Tong A, Sainsbury P, Craig J. Consolidated criteria for reporting qualitative research (COREQ): a 32-item checklist for interviews and focus groups. Int J Qual Health Care 2007:19:349-57.

33. Fox AM, Jackson SS, Hansen NB, et al. In their own voices a qualitative study of women's risk for intimate partner violence and HIV in South Africa. Violence Against Women 2007;13:583-602.

34. Devries KM, Child JC, Bacchus LJ, et al. Intimate partner violence victimization and alcohol consumption in women: a systematic review and meta-analysis. Addiction 2014;109:379-91.

35. Ezechi OC, Gab-Okafor C, Onwujekwe DI, et al. Intimate partner violence and correlates in pregnant HIV positive Nigerians. Arch Gynecol Obstet 2009;280:745-52.

36. Panos Institute Southern Africa. Media brief on prevention of mother-to-child transmission (PMTCT) of HIV in Swaziland. Lusaka, Zambia: Panos, 2012

37. Gari S, Malungo JRS, Martin-Hilber A, et al. HIV testing and tolerance to gender based violence: a cross-sectional study in Zambia. PLOS ONE 2013;8:e71922.

38. Jewkes R, Morrell R. Gender and sexuality: emerging perspectives from the heterosexual epidemic in South Africa and implications for HIV risk and prevention. J Int AIDS Soc 2010;13:6.

39. Howard N, Von Maerker A, Colombini M. "There's a man and then there's a male person...": a qualitative analysis of masculinity in relation to male sexual and reproductive health in Swaziland. in preparation.

40. Mayhew SH, Colombini M, Tomlin K. "I do not like getting a baby when I have not planned..." Fertility intentions, contraceptive practices and inappropriately met need, among service-users living with HIV in Kenya. PLoS Med Submitted. Forthcoming.

41. Mlay R, Lugina H, Becker S. Couple counselling and testing for HIV at antenatal clinics: views from men, women and counsellors. AIDS Care 2008;20:356-60.

42. Emusu D, Ivankova N, Jolly $\mathrm{P}$, et al. Experience of sexual violence among women in HIV discordant unions after voluntary HIV counselling and testing: a qualitative critical incident study in Uganda. AIDS Care 2009;21:1363-70.

43. Feirman S. Men's susceptibility to HIV in Swaziland. Cult Health Sex 2012;14:723-35. 